Received: 16.10 .2018

Revised: 26.08.2019

Accepted: 25.10 .2019

DOI: $10.17804 / 2410-9908.2019 .5 .040-047$

\title{
DESIGN AND PROCESS DESCRIPTION OF WELDED JOINTS IN GENERAL-PURPOSE STRUCTURAL STEELS
}

\author{
Z. G. Kornilova ${ }^{\text {a) }}$ and G. S. Ammosov ${ }^{\text {b** }}$ \\ V. P. Larionov Institute of Physical-Technical Problems of the North, \\ Siberian Branch of the Russian Academy of Sciences, \\ 1 Oktyabrskaya St., Yakutsk, 677980, Russian Federation \\ a) iD https://orcid.org/0000-0001-8516-3076 _oya_korn@mail.ru; \\ b) iD https://orcid.org/0000-0002-1098-6024 ه ammosov.g@mail.ru \\ *Corresponding author: E-mail: ammosov.g@mail.ru \\ Address for correspondence: ul. Oktyabrskaya, 1, Yakutsk, 677980, Russian Federation \\ Tel.: +7 (4112) $390587 ; 89142268991$
}

Ensuring the durability and longevity of welded joints in metallic structures is an important problem of life support, especially in the conditions of the North. Welded joints are the crucial areas reducing resistance to brittle failure, and heat-affected zones (HAZ) are their weakest sites in terms of cold resistance. Thermokinetic diagrams and diagrams of anisothermal decay of austenite (ADA) are used for the determination of the structure composition and mechanical characteristics of the HAZ metal in the welding of many structural steels for various purposes. To choose optimum rates of cooling by preheating of products to be welded, the structure composition and mechanical characteristics of the HAZ metal, we use a carbon equivalent $\mathrm{C}_{\mathrm{e}}$. Besides, in terms of the effect of design and process factors on the formation of welded joints, the paper shows the necessity of controlling welding consumables when welding general-purpose steels.

Keywords: welded joint, brittle failure, defect, crack, heat-affected zone, deposit rate factor, heat input.

\section{References}

1. Antonov A.A, Yakovlev Yu.A., Ammosov A.P. Estimation of the corrosion damageability of the metal of a steam pipeline that has worked its design life. In: Welding and Safety: Materials of the Scientific Research and Production Association, October 11-12, 2012, vol. 1. Yakutsk, Offset Publ., 2012, pp. 264-66. (In Russian).

2. Andriyashin V.A., Kostyuchenko A.A., Komarov A.I., Vorob'ev V.V., Andriyashin V.A. Long-Term Inside Corrosion Attack of an Oil Main Operation. Protection of Metals, 2006, vol. 42, no. 1, pp. 46-50. DOI: 10.1134/S0033173206010085.

3. Ammosov A.P., Ammosov G.S., Aminov T.Sh., Ilin G.Yu., Antonov A.A. Corrosive damageability of the reservoir welded joints. Svarochnoe Proizvodstvo, 2008, no. 7, pp. 24-28. (In Russian).

4. Vasiliev V.G., Dovzhenko V.A., Malevsky Yu.B. Residual austenite in welded joints of low-carbon low-alloy structural steels. Avtomaticheskaya Svarka, 1978, no. 8, pp. 5-8. (In Russian).

5. Seyffarth P., Kuscher G. Schweiss-ZTV-Schaubilder, Berlin, VEB Verlag Technik, 1982.

6. Marochnik staley $i$ splavov [Register of Steels and Alloys, ed. by A.S. Zubchenko]. Moscow, "Mashinoctroenie" Publ., 2001. (In Russian). 
7. Ammosov A.P., Kornilova Z.G. Controlling the consumption of welding consumables in welding low-alloy pipe steels. Welding production, 2006, vol. 20, iss. 8, pp. 665-668. DOI: $10.1533 /$ wint.2006.3673.

8. Zakharova I.V., Chichkarev E.A., Vasiliev V.G., Trotsan A.I., Dejneka A.Ya., and Kiryukhin O.S. Structure and properties of HAZ metal of low-alloyed pipe steels modified with calcium. The Paton Welding Journal, 2001, no. 8, pp. 14-17. (In Russian).

9. Ammosov A.P., Kornilov Z.G. Consumption of electrodes in manual arc welding of metal structures. Welding International, 2004, vol. 18, iss. 6, pp. 478-479. DOI: 10.1533/wint.2004.3306.

10. Panashchenko N.I., Masur A.A., Parnau A.K., Beynish A.M. The methods of calculating the consumption of coated electrodes and electric energy in the manufacture of welded structures. Avt. Svarka, 1995, no. 8, pp. 39-46. (In Russian).

11. Fedotova M.A., Larionov V.P. et al. Structural Transformations and Properties of Materials in Welding. YaNTs SO AN SSSR, Yakutsk, 1991, 25 p. (In Russian).

12. Tararychkin I.A. Optimisation of the shape of edge preparation in narrow-gap arc welding Optimization of a form of cutting of edges at arc welding in a narrow gap. Svar. Proiz., 2001, no. 10, pp. 21-23. (In Russian). 
Подана в журнал: 16.10 .2018

УДК (621.791:669.14):624.014

DOI: $10.17804 / 2410-9908.2019 .5 .040-047$

\title{
КОНСТРУКТИВНО-ТЕХНОЛОГИЧЕСКОЕ ОФОРМЛЕНИЕ СВАРНЫХ СОЕДИНЕНИЙ КОНСТРУКЦИОННЫХ СТАЛЕЙ МАССОВОГО НАЗНАЧЕНИЯ
}

\author{
3. Г. Корнилова ${ }^{\text {a) }}$, Г. С. Аммосов ${ }^{\text {б)* }}$ \\ Институт физико-технических проблем Севера им. В.П. Ларионова СО РАН, \\ д. 1, ул. Октябрьская, г. Якутск, Российская Федерация \\ a) (iD https://orcid.org/0000-0001-8516-3076 zoya_korn@mail.ru; \\ б) (iD https://orcid.org/0000-0002-1098-6024 ه ammosov.g@mail.ru \\ *Ответственный автор. Электронная почта: ammosov.g@mail.ru \\ Адрес для переписки: ул. Октябрьская, д. 1, 677980, г. Якутск, Российская Федерация \\ Тел.: +7 (4112) 39-05-87; 8-914-226-89-91
}

Обеспечение прочности и долговечности сварных соединений металлоконструкций является одной из важных задач жизнеобеспечения, особенно в условиях Севера. Ответственными участками, снижающими сопротивляемость хрупкому разрушению, являются сварные соединения, а наиболее слабыми местами сварных соединений с позиции хладостойкости - зона термического влияния (ЗТВ). Термокинетические диаграммы, диаграммы анизотермического распада аустенита (АРА) используются для определения состава структуры и механических свойств в металле ЗТВ при сварке многих конструкционных сталей различного назначения. Для выбора оптимальных скоростей охлаждения предварительным подогревом свариваемых изделий, состава структуры и механических свойств в металле ЗТВ используется эквивалент углерода $C_{\text {э }}$. Также в работе показана необходимость регулирования расхода сварочных материалов при сварке сталей массового назначения с позиции влияния конструктивно-технологических факторов на процессы формирования сварных швов.

Ключевые слова: сварные соединения, хрупкие разрушения, дефекты, трещина, зона термического влияния, коэффициент наплавки, погонная энергия.

\section{1. Введение}

Одним из распространенных факторов обеспечения надежности сварных металлоконструкций, элементов горной техники и линейных сооружений, эксплуатирующихся в условиях Крайнего Севера, является минимизация возникновения хрупких разрушений.

При хрупких разрушениях различных сооружений судов, напорных труб, высотных сооружений, емкостей и резервуаров для хранения нефти, нефтепродуктов и газа, сосудов высокого давления, трубопроводных систем, мостовых переходов через малые и крупные реки и т. д. наиболее часто очагами возникновения и распространения трещин являются сварные соединения, являющиеся конструктивно неоднородными участками и формирующиеся при монтаже многих крупноразмерных металлоконструкций, элементов техники, а также протяженных линейных сооружений.

Во многих случаях основными очагами возникновения трещин служат различные технологические и эксплуатационные микро- и макро- дефекты - непровары, подрезы, скопления пор, шлаковые включения, риски, трещины и другие дефекты. Возникновению разрушения способствуют низкие температуры, высокий уровень остаточных напряжений $(\mathrm{OH})$ в зонах шва (ЗШ), наличие дефектов (трещин) в сварных соединениях, связанных с технологией сварки и накоплением усталости. 
Особенность металлических конструкций состоит в том, что наступление предельного состояния и разрушения хотя бы одного конструктивного элемента вызывает аварию всего сложного сооружения.

Характерным является и тот факт, что для многих металлоконструкций и линейных сооружений частота разрушений повышается при начальной стадии эксплуатации и при приближении к проектным срокам их эксплуатации. Такая статистика объясняется тем, что разрушения в начальной стадии эксплуатации ответственных объектов, скорее всего, связаны с некоторыми технологическими упущениями при строительстве и проектировании сооружений, а на конечной стадии эксплуатации увеличение частоты разрушений объясняется накоплением эксплуатационных и коррозионных повреждений.

Цель исследования - изучение конструктивно-технологических факторов на процессы формирования сварных швов.

\section{2. Материал и методика}

Одна из особенностей коррозионных повреждений - наиболее интенсивное протекание коррозионных повреждений в металле зоны термического влияния (ЗТВ) сварных соединений паропроводов, магистральных и технологических нефтепроводов, резервуаров для хранения нефти и нефтепродуктов $[1,2,3]$. Измерение коррозионного износа проводилось методом ультразвуковой толщинометрии с применением ультразвукового толщиномера «Булат 1м» по нормативно технической документации для каждого объекта.

Возникновение сквозных трещин во многих случаях связано с увеличением размера пор, раковин и подрезов, обнаруженных методом визуально-измерительного контроля нормируемым РД 03-606-03, в результате развития коррозионных повреждений под напряжением (рис. 1). Постепенно из скоплений пор и включений вырастают несквозные свищи и при дальнейшей эксплуатации резервуара в таких местах сварного соединения возникают поверхностные или сквозные трещины в результате слияния свищей.

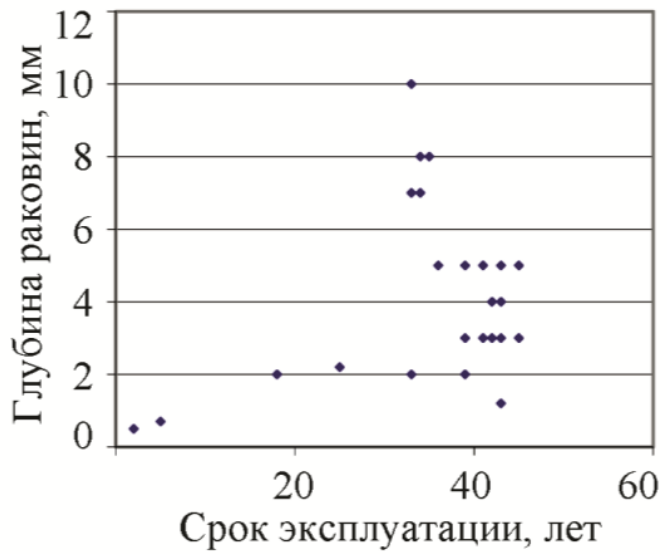

$a$

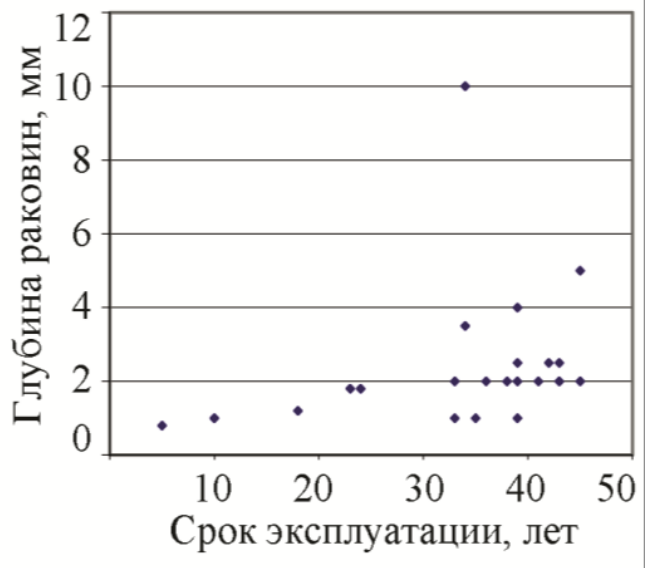

$\sigma$

Рис. 1. Глубина дефектов сварного соединения уторного узла резервуара из стали ВСт3сп от срока эксплуатации: $a$ - раковины; $\sigma$ - подрезы

В качестве примера приведем разрушение днища резервуара по монтажным швам (рис. 2 a) длиной 665 мм и более. Аналогичное возникновение трещины произошло в кратере (рис. 2 б). Возникновение таких трещин в сварных соединениях листов днища резервуаров обусловлено низким качеством сварных швов, климатическими условиями Севера, особенностями промерзания и протаивания грунтов оснований резервуаров и другими технологическими и конструктивными недоработками, а также накоплением коррозионных повреждений. 


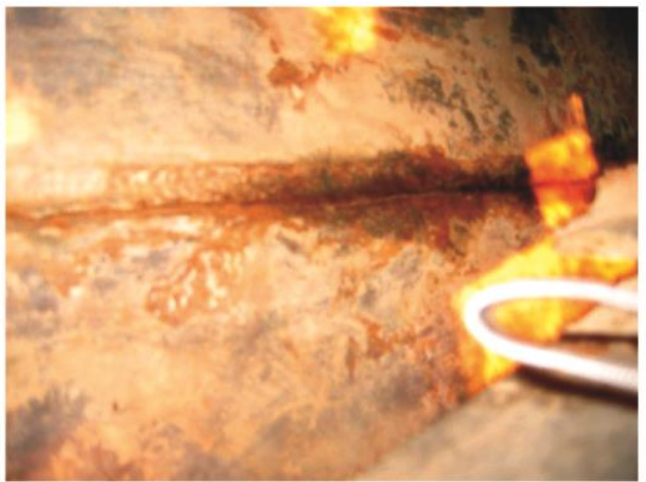

$a$

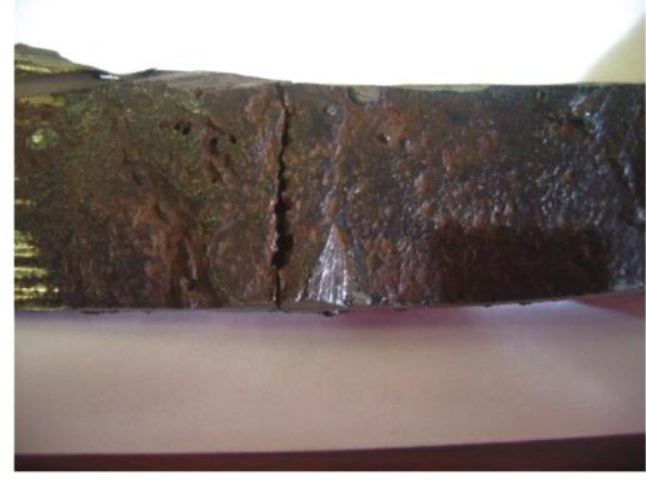

$\sigma$

Рис. 2. Трещины в монтажном шве листов днища (a) и в перекрестиях швов днища (б)

При этом размеры большинства сварных соединений соответствуют или превышают требования ГОСТ 5264-80, ГОСТ 14771-76. Здесь, на наш взгляд, высокой коррозионной повреждаемости способствуют наличие остаточных сварочных напряжений, конструктивно-технологических концентраторов, а также возникших в процессе сварки допустимых технологических дефектов, таких как непровары, поры, шлаковые включения, микротрещины, которые вследствие эксплуатации развиваются под воздействием коррозионно-агрессивных сред.

В таких соединениях твердость металла ЗТВ бывает ниже твердости основного металла. Это, скорее всего, связано с тем, что сварка производится при высоких погонных энергиях и в единицу длины шва наплавляется большое количество электродного металла.

Известно, что наиболее распространенным подходом определения состава структуры и механических свойств в металле ЗТВ при сварке многих конструкционных сталей различного назначения являются термокинетические диаграммы, а также диаграммы анизотермического распада аустенита (АРА), полученные в лабораторных условиях на специальных скоростных дилатометрах имитацией термических циклов сварки малоразмерных образцов. Для выбора оптимальных скоростей охлаждения предварительным подогревом свариваемых изделий, состава структуры и механических свойств в металле 3ТВ, используется эквивалент углерода $C_{э}$, вычисляемый по химическому составу свариваемых сталей. Для сталей большинства марок построены термокинетические диаграммы или диаграммы АРА и определены допустимые скорости охлаждения металла в 3ТВ, обеспечивающие оптимальные структуры и механические свойства [4-6].

По оптимизации конструктивно-технологического оформления сварных швов ответственных сооружений, эксплуатирующихся в сложных природно-климатических условиях, проводятся систематические работы.

Наиболее применяемым технологическим процессом ремонтно-восстановительных работ локальных повреждений резервуаров является сварка. С учетом этого после завершения натурных обследований и технической диагностики резервуаров в зависимости от степени и места локальной коррозионной поврежденности их элементов разрабатывается технологическая карта ремонтно-восстановительных работ, где предусматривается тщательная зачистка, подготовка разделки кромок и конструктивно-технологическое оформление ремонтных сварных швов и облицовочных наплавок. При этом учитываются выбор и расход сварочных материалов, режимы сварки и наплавки. Нормирование расхода сварочных материалов повышает эффективность производства металлоконструкций и трубопроводных систем. В работе [7] рассмотрена возможность регулирования расхода сварочных материалов на основе определения площади поперечного сечения шва при сварке низколегированных сталей 13Г1СУ, 09Г2ФБ, 10Г2ФБ, модифицированных кальцием. С использованием данных работы [8] 
полученные результаты приведены в сравнении с нормативными требованиями стандартов к поперечному сечению наплавленного с учетом формы разделки кромок свариваемых изделий. В таблице приведены полученные расчетные данные и нормативные значения поперечных сечений сварных швов $\left(S_{i}\right)$ при различных видах сварки.

Значения площади поперечных сечений сварных швов с учетом видов сварки

\begin{tabular}{|c|c|c|c|c|}
\hline $\begin{array}{c}\text { Технологический } \\
\text { процесс }\end{array}$ & $\begin{array}{c}\text { Толщина } \\
\text { пластины } \\
\delta, \text { мм }\end{array}$ & Тип шва & ГОСТ & $\begin{array}{c}\text { Площадь } \\
\text { поперечного } \\
\text { сечения шва } S_{i}, \text { мм }^{2}\end{array}$ \\
\hline $\begin{array}{c}\text { Автоматическая сварка } \\
\text { сплошной проволокой } \\
\text { под флюсом (АСФ) }\end{array}$ & $\begin{array}{c}12,0 \\
20,0\end{array}$ & $\begin{array}{c}\text { С10-Аф или } \\
\text { С10-Ам } \\
\text { С15-Апк }\end{array}$ & $8713-70$ & $\begin{array}{c}85,76 \\
274,6\end{array}$ \\
\hline $\begin{array}{c}\text { Механизированная } \\
\text { сварка в углекислом } \\
\text { газе (МС) }\end{array}$ & 12,0 & С17-УП & $\begin{array}{c}14771- \\
69\end{array}$ & $\begin{array}{c}63,03^{* * *} \\
159,32^{* * *}\end{array}$ \\
\hline $\begin{array}{c}\text { Ручная дуговая сварка } \\
\text { (РдС) }\end{array}$ & 12,0 & С15* & $5264-69$ & $86,228^{* *}$ \\
\hline
\end{tabular}

${ }^{*}$ Соответствует С17 по ГОСТ 5264-80

${ }^{* *}$ Соответствует предельным размерам по ГОСТ 5264 - 80 п.16

*** Соответствует С17-УП по ГОСТ $14771-76$

Изменение количества наплавленного металла в шве, в частности его поперечное сечение $S_{i}$, рассчитанное в [9]:

$$
S_{i}=\frac{a_{H} q_{\Pi}}{\eta U \gamma}
$$

где: $a_{н}$ - коэффициент наплавки; $q_{\Pi}-$ погонная энергия, кДж/см; $\eta$ - эффективный коэффициент передачи тепла; $U$ - напряжение дуги, В; $\gamma$ - плотность металла шва.

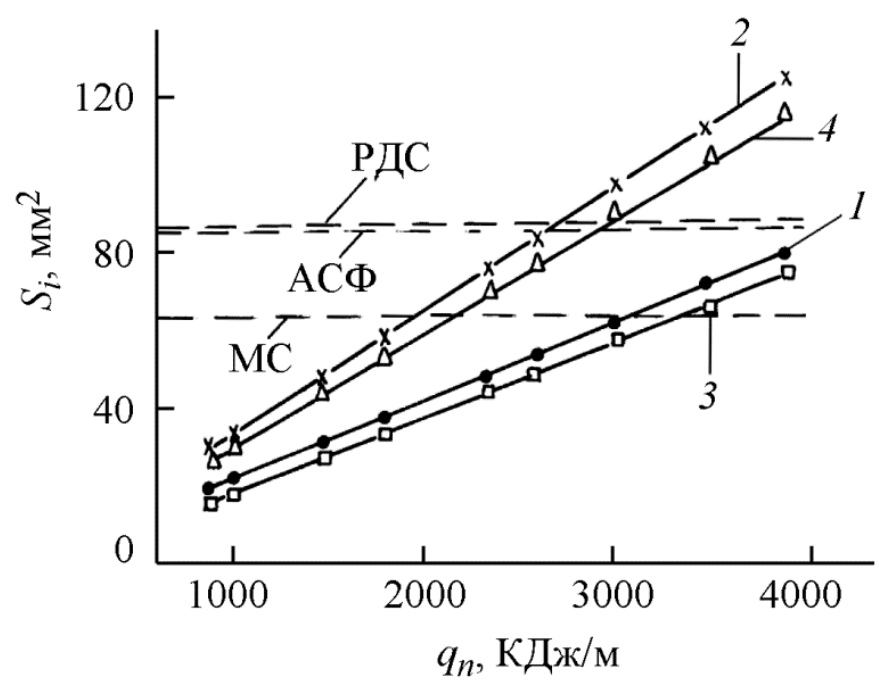

Рис. 3. Зависимость поперечного сечения наплавленного металла от погонной энергии сварки при $U=22 \mathrm{D}, a_{\mu}$, равном 9,5 (1) и 15 (2) г/(А·ч), и $U=22 \mathrm{~B} ; a_{t}$, равном 9,5 (3)

$$
\text { и } 15 \text { (4) г/(А·ч) }
$$


При $q_{\Pi}=8,9 \div 39,2$ кДж/см; $a_{н}$ (коэффициент наплавки), равном 9,5 и 15 г/(А·ч); $U$,

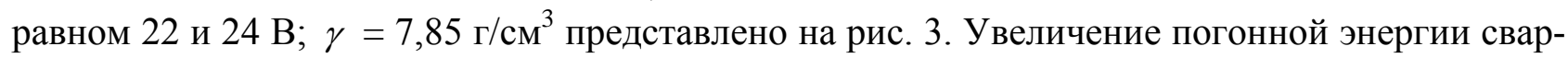
ки и коэффициента наплавки повышает площадь поперечного сечения наплавленного металла, повышение напряжения дуги снижает ее.

Сопоставление расчетных данных (рис. 3) и нормативных требований показывает, что при $\delta=12$ мм и $a_{н}=9,5$ г/(А·ч) полное заполнение шва при АСФ и РДС за один проход не достигается. Количество проходов определяется погонной энергией сварки $q_{\Pi}$. Например, при МС в углекислом газе полное заполнение шва за один проход достигается при значениях $a_{н}$, равных 15,0 и 9,5 г/(А·ч), $\delta=12$ мм и погонной энергии 1980-2160 и 3120-3500 кДж/см соответственно.

Связывая погонную энергию сварки $q_{\text {п }}$ со скоростью охлаждения $W_{6 / 5}$ получаем (2) из [9]

$$
S_{i}=\frac{a_{H} k_{1}}{W_{6 / 5} U \gamma \eta},
$$

где: $a_{н}$ - коэффициент наплавки; $k_{1}-$ коэффициент, зависящий от начальной температуры и толщины (размера) свариваемого изделия; $U$ - напряжение дуги, В; $\gamma$ - плотность металла шва; $W_{6 / 5}$ - скорость охлаждения, ${ }^{\circ} \mathrm{C} / \mathrm{c} ; \eta$ - эффективный коэффициент передачи тепла.

\section{3. Результаты и обсуждение}

Установили, что площадь сечения наплавленного металла шва за проход и скорость охлаждения являются взаимозависимыми величинами. Диапазон рекомендуемых оптимальных скоростей охлаждения для каждой стали различен, а для допустимых площадей наплавленного металла за проход его можно выбрать исходя из обеспечиваемых физикомеханических свойств металла перегрева.

Таким образом, допустимые размеры разделок кромок свариваемых изделий и методы расчета расхода, покрытых электродов [9] могут быть скорректированы в определенных пределах при выборе технологии сварки с учетом термодеформационного цикла сварки. Прочностные характеристики зоны перегрева сварного соединения получаются оптимальными, что позволяет значительно продлить остаточный ресурс сварных конструкций, проработавших на Севере в течение 30 и более лет. Это подтверждается результатами исследований [11] и технологией сварки различных сталей в узкую разделку или без разделки кромок [12].

\section{4. Заключение}

Следовательно, на основе изучения и анализа закономерностей термокинетических процессов в углеродистых и низколегированных сталях при сварке, особенностей формирования структуры в металле ЗТВ сварного соединения, существующих допусков в нормативных документах обоснована необходимость регулирования расхода сварочных материалов при сварке сталей массового назначения с позиции влияния конструктивно-технологических факторов на процессы формирования сварных швов. Обобщение физико-химических и технологических процессов наплавки в разделку при электродуговой сварке позволило выработать расчетные зависимости, связывающие количество наплавленного металла в шов с погонной энергией, скоростью охлаждения металла 3ТВ, коэффициентом наплавки, толщиной и начальной температурой свариваемого изделия, а также количеством проходов [9]. Эти научнообоснованные, производственно-направленные результаты непосредственно исполь- 
зуются для разработки технологии ремонтно-восстановительной сварки, а также технологии монтажной сварки при строительстве ответственных крупноразмерных металлоконструкций и линейных сооружений, работающих в экстремальных условиях Севера.

\section{Литература}

1. Антонов А. А., Яковлев Ю. А., Аммосов А. П. Оценка коррозионной повреждаемости металла паропровода, отработавшего расчетный срок эксплуатации // «Сварка и безопасность», 11-12 октября 2012, Якутск. Том 1 : материалы ВРНПК. - Якутск : ООО РИЦ «Офсет», 2012. - C. 264-266.

2. Long-Term Inside Corrosion Attack of an Oil Main Operation / V. A. Andriyashin, A. A. Kostyuchenko, A. I. Komarov, V. V. Vorob'ev, V. A. Andriyashin // Protection of Metals. 2006. - Vol. 42, no. 1. - P. 46-50. - DOI: 10.1134/S0033173206010085.

3. Коррозионная поврежденность сварных соединений резервуаров / А. П. Аммосов, Г. С. Аммосов, Т. Ш. Аминов, Г. Ю. Ильин, А. А. Антонов // Сварочное производство. 2008. - № 7. - С. 24-28.

4. Васильев В. Г., Довженко В. А., Малевский Ю. Б. Остаточный аустенит в сварных соединениях низкоуглеродистых низколегированных конструкционных сталей // Автоматическая сварка. - 1978. - № 8. - С. 5-8.

5. Seyffarth P., Kuscher G. Schweiss-ZTV-Schaubilder. - Berlin : VEB Verlag Technik, 1982. $236 \mathrm{p}$.

6. Марочник сталей и сплавов / под ред. А. С. Зубченко. - М. : Машиностроение, 2001. $672 \mathrm{c}$.

7. Ammosov A. P., Kornilova Z. G. Controlling the consumption of welding consumables in welding low-alloy pipe steels // Welding production. - 2006. - Vol. 20, iss. 8. - P. 665-668. DOI: $10.1533 /$ wint.2006.3673.

8. Zakharova I. V., Chichkarev E. A., Vasiliev V. G., Trotsan A. I., Dejneka A. Ya., and Kiryukhin O. S. Structure and properties of HAZ metal of low-alloyed pipe steels modified with calcium // The Paton Welding Journal. - 2001. - No. 8. - P. 14-17.

9. Ammosov A. P., Kornilov Z. G. Consumption of electrodes in manual arc welding of metal structures // Welding International. - 2004. - Vol. 18, iss. 6. - P. 478-479. DOI: $10.1533 /$ wint.2004.3306.

10. Методы расчета расхода покрытых электродов и электроэнергии при изготовлении сварных конструкций / Н. И. Панащенко, А. А. Мазур, А. К. Парнау, А. М. Бейниш // Автоматическая сварка. - 1995. - № 10. - С. 39-47.

11. Структурные превращения и свойства материалов при сварке / М. А. Федотова, А. П. Аммосов, В. П. Ларионов, П. И. Зайффарт, Х.-Г. Гросс, Л. Фишер, Л. Мраз // Якутск : ЯНЦ СО АН СССР, препринт, 1991. - 25 с.

12. Тарарычкин И. А. Оптимизация формы разделки кромок при дуговой сварке в узкий зазор // Сварочное производство. - 2001. - № 10. - С. 21-23. 